University of Nebraska - Lincoln

DigitalCommons@University of Nebraska - Lincoln

\title{
Does Bisphenol A Induce Superfeminization in Marisa cornuarietis? Part II: Toxicity Test Results and Requirements for Statistical Power Analyses
}

\author{
Valery E. Forbes \\ University of Nebraska-Lincoln, veforbes@umn.edu \\ John Aufderheide \\ ABC Laboratories, Inc., Columbia, Missouri \\ Ryan Warbritton \\ ABC Laboratories, Inc., Columbia, Missouri \\ Nelly van der Hoeven \\ Ecostat, Leiden, The Netherlands \\ Norbert Caspers \\ Bayer Industry Services, Leverkusen, Germany
}

Follow this and additional works at: https://digitalcommons.unl.edu/biosciforbes

Part of the Pharmacology, Toxicology and Environmental Health Commons

Forbes, Valery E.; Aufderheide, John; Warbritton, Ryan; van der Hoeven, Nelly; and Caspers, Norbert, "Does Bisphenol A Induce Superfeminization in Marisa cornuarietis? Part II: Toxicity Test Results and Requirements for Statistical Power Analyses" (2007). Valery Forbes Publications. 26.

https://digitalcommons.unl.edu/biosciforbes/26

This Article is brought to you for free and open access by the Papers in the Biological Sciences at DigitalCommons@University of Nebraska - Lincoln. It has been accepted for inclusion in Valery Forbes Publications by an authorized administrator of DigitalCommons@University of Nebraska - Lincoln. 


\title{
Does Bisphenol A Induce Superfeminization in Marisa cornuarietis? Part II: Toxicity Test Results and Requirements for Statistical Power Analyses
}

\author{
Valery E. Forbes, ${ }^{1}$ John Aufderheide, ${ }^{2}$ Ryan Warbritton, ${ }^{2}$ \\ Nelly van der Hoeven, ${ }^{3}$ Norbert Caspers ${ }^{4}$
}

\author{
1. Department of Environmental, Social and Spatial Change, Roskilde University, Roskilde, Denmark \\ (Corresponding author; affiliation 2010- University of Nebraska-Lincoln, \\ Lincoln, Nebraska, USA; vforbes3@unl.edu ) \\ 2. ABC Laboratories, Inc., Columbia, Missouri, USA \\ 3. Ecostat, Leiden, The Netherlands \\ 4. Bayer Industry Services, Leverkusen, Germany
}

\begin{abstract}
This study presents results of the effects of bisphenol A (BPA) on adult egg production, egg hatchability, egg development rates and juvenile growth rates in the freshwater gastropod, Marisa cornuarietis. We observed no adult mortality, substantial inter-snail variability in reproductive output, and no effects of BPA on reproduction during 12 weeks of exposure to $0,0.1,1.0,16,160$ or $640 \mu \mathrm{g} / \mathrm{L}$ BPA. We observed no effects of BPA on egg hatchability or timing of egg hatching. Juveniles showed good growth in the control and all treatments, and there were no significant effects of BPA on this endpoint. Our results do not support previous claims of enhanced reproduction in Marisa cornuarietis in response to exposure to BPA. Statistical power analysis indicated high levels of inter-snail variability in the measured endpoints and highlighted the need for sufficient replication when testing treatment effects on reproduction in $M$. cornuarietis with adequate power.
\end{abstract}

Keywords: endocrine disruption, low-dose effects, reproduction, risk assessment, statistical power, variability

\section{Introduction}

Bisphenol A (BPA; 4,4-isopropylidene diphenol) is a chemical intermediate used primarily in the production of epoxy resins and polycarbonate products. Specific uses include impact-resistant eyeglass lenses, food and beverage containers, helmets, compact discs, fire retardants, production of polyvinyl chloride and other plastics (Staples et al., 1998; EC, 2003). The available literature on the environmental toxicology of bisphenol A has been critically reviewed (Staples et al., 2002, EC, 2003), and the compound is known to exhibit weak estrogenic activity. Several recent papers by Oehlmann and colleagues have claimed that BPA induces superfeminization in the gastropod Marisa cornuarietis at environmentally relevant ex- posure concentrations. These effects include formation of additional female organs, enlarged accessory sex glands, gross malformations of the pallial oviduct, and a stimulation of egg and egg mass production resulting in increased female mortality (Oehlmann et al., 2000; SchulteOehlmann et al., 2001; Oehlmann et al., 2006a). If these claims are valid, they can have an important influence on the risk assessment for this chemical, since, on the basis of the above results, $M$. cornuarietis would seem to be more sensitive than all other aquatic invertebrates so far tested.

However, there are a number of problems with using Marisa cornuarietis in ecotoxicological testing. These include a lack of basic knowledge of the husbandry requirements of the species and the variability of its lifehistory traits and key endpoints (e.g., fecundity, hatch- 
ability, etc.) under laboratory conditions. In addition, the published studies claiming effects of BPA on this species (Oehlmann et al., 2000, 2006a; Schulte-Oehlmann et al., 2001) have been hotly debated (Dietrich et al., 2006, Oehlmann et al., 2006b). The present study aims to contribute new data to this ongoing debate.

Part I of this two-part series (Forbes et al., accepted) quantified and identified sources of variability in key test endpoints under controlled laboratory conditions to establish baseline values and determine experimental design requirements. In Part II of this series we provide preliminary results of the effects of BPA on Marisa cornuarietis and, on the basis of these results, perform a statistical power analysis and demonstrate how such analyses can be used to design robust and powerful tests for detecting effects of BPA on this species. Our results highlight the need for proper replication and power analyses when deriving conclusions about chemical effects that can have important impacts on the regulation of such chemicals.

\section{Materials and methods}

\subsection{Culture establishment and conditions}

Wild specimens of M. cornuarietis were collected from Lake Guajataca, Puerto Rico (see Aufderheide et al. (2006), for site details and collection methods) and transported to ABC Laboratory, at which the present experiments were performed. The snails were cultured under conditions similar to those specified for testing purposes. A $12 \mathrm{~h}$ light: $12 \mathrm{~h}$ dark photoperiod with two 30 min transition periods was used with illumination provided by fluorescent lights at an intensity range of 400-800 lux. The cultures were set up on a single-pass flow-through system to maintain adequate water quality (i.e., dissolved oxygen, temperature, and $\mathrm{pH}$ ). Water temperature of cultures was maintained at $25^{\circ} \mathrm{C}$. Snails were fed fresh, commercially purchased organically grown romaine lettuce (Lactuca sativa, romaine) and commercial algal wafers (supplied by Hikari, USA, http://www.hikariusa.com/ tropical/algaewafers).

\subsection{Experimental design}

This study was designed and performed according to the OECD principles of good laboratory practice (GLP) (OECD 1997). The endpoints we chose for this study are adult fecundity, egg hatchability and development rate and juvenile growth rate since these endpoints are less subjective and more amenable to statistical analysis than morphological or histological endpoints. In addition, they cover the main stages of the life cycle and can be combined to give a measure of effect at the population-level (Forbes and Calow, 1999).

The adult snails used to initiate the BPA trials were cultured at $\mathrm{ABC}$ Laboratories (e.g., $F_{4}$ and $F_{6}$ generations). Males were in the size range of 31.4-41.7 $\mathrm{mm}$ diameter and females were in the range 36.4$47.5 \mathrm{~mm}$ diameter. Previous work has shown snails in this size range to be reproductively active (Aufderheide et al., 2006). Snails were impartially allocated among replicate aquaria and chambers.

Each adult replicate consisted of a glass aquarium (approximate base dimensions $60 \times 30 \mathrm{~cm}$ ) containing a working volume of $25 \mathrm{~L}$ of test solution. Each replicate was segregated into 10 equal size chambers using perforated glass partitioning and received 10 volume additions of water per day. The water delivery system was split between the 10 chambers so that water addition was similar among the 10 chambers. The test chambers were immersed in a circulating water bath adjusted to maintain the water temperature at $25 \pm 1{ }^{\circ} \mathrm{C}$, which was measured continuously using a Multi-Scan temperature probe positioned centrally in one of the centrally located replicate aquaria.
One breeding pair of $M$. cornuarietis was placed into each chamber resulting in a density of $\sim 0.8$ snails/L.

Each breeding pair was fed the two food types three times per week in amounts of approximately $2 \mathrm{~g}$ of lettuce and $0.5 \mathrm{~g}$ of an algal wafer. Any old food was removed on the next feeding occasion. Each replicate was cleaned by siphoning feces and uneaten food particles three times per week just prior to the addition of new food. Aquarium walls were wiped once per week, and glass partitions were removed and cleaned individually as needed.

\subsection{Dilution water and test chemical}

The dilution water was a laboratory freshwater prepared by blending naturally hard well water with well water that was demineralized by reverse osmosis. These water types were blended to yield a total hardness of $130-160 \mathrm{mg} / \mathrm{L}$ as $\mathrm{CaCO}_{3}$ and a calcium content of approximately $30 \mathrm{mg} / \mathrm{L}$. Calcium chloride dihydrate $\left(\mathrm{CaCl}_{2}\right.$ - $2 \mathrm{H}_{2} \mathrm{O}$ ) was mixed with the laboratory freshwater prior to delivery into the diluter system in order to increase the total calcium content to within a range of $60-90 \mathrm{mg} / \mathrm{L}$. Prior to the initiation of the studies and at least once during the course of the studies, calcium content was measured from duplicate samples of dilution water collected near the drain of one of the control replicate chambers. The direct calcium content measurements were equated to total hardness values, and test solution hardness was monitored on a weekly basis to demonstrate adequate calcium addition. Calcium analysis was conducted by ICP-MS (Perkin-Elmer ELAN 6000, Perkin-Elmer Life \& Analytical Sciences, Wellesley, MA, USA) according to standard methodology (EPA method 200.8, Creed et al., 1994). The dissolved oxygen concentrations were kept at $\geq 60 \%$ of saturation in the test solutions throughout the test. Test replicates were aerated to maintain dissolved oxygen concentrations above this level. The test solution temperature, dissolved oxygen, and $\mathrm{pH}$ content were measured once per week.

BPA test concentrations were prepared in the following nominal concentrations: 0 (control), 0.10, 1.0, 16, 160, and $640 \mu \mathrm{g} \mathrm{BPA/L.} \mathrm{A}$ modified proportional diluter system (Mount and Brungs, 1967) was used to intermittently introduce test substance and dilution water into the test chambers. The diluter system was volumetrically calibrated before test initiation and inspected at least twice each day during the tests for function and stock usage, and the metering pumps were checked weekly for delivery volumes. Stock was prepared weekly and added to the stock bottle on the diluter daily or as needed. The diluter system was set-up to deliver dilution water or test solutions to each test vessel for a minimum equilibration period of 14 days prior to addition of the test organisms.

Analytical confirmation of the test solution BPA concentrations was performed by high performance liquid chromatography (HPLC; Agilent 1100; Agilent Technologies Inc., Palo Alto, California, USA) with UV fluorescence detection (excitation wavelength $=230 \mathrm{~nm}$; emission wavelength $=280 \mathrm{~nm}$ ). A Zorbax Eclipse XDB C8 column (15 $\mathrm{cm} \times 4.6 \mathrm{~mm}$ ), a mobile phase (Isocratic) of 65:35 methanol: deionized water, a flow rate of $1 \mathrm{~mL} / \mathrm{min}$, and an injection volume of $900 \mu \mathrm{L}$ were used.

BPA concentrations were measured twice during the equilibration period, at test initiation, weekly during the adult fecundity and juvenile growth trials, twice a week during the hatchability trials, and at test termination. The analytical samples were composites of equal volume sub-samples collected from each replicate aquarium.

\subsection{Adult fecundity trial}

An adult fecundity trial was performed for a 12-week period. Three replicate test vessels with 10 breeding pairs were tested at each test concentration (i.e., 30 pairs per treatment level $\times 6$ levels $=180$ adult pairs). Chambers were checked three times weekly for the presence of eggs. Both numbers of egg masses and numbers of eggs per egg mass were recorded. When preparing to collect eggs for hatchability trials (see below), adults were checked daily so that the exact date of egg deposition used in the hatchability trials could be determined. 
To quantify the effect of BPA exposure on egg production, nested analysis of variance (ANOVA) was used (Sokal and Rohlf, 1995) in which replicate aquaria were nested within BPA treatments, and the dependent variable was eggs/female/month (averaged for each female over the entire trial; $n=10$ per replicate aquarium).

\subsection{Egg hatchability trial}

A hatchability trial was started two months after the initiation of the adult fecundity trial. Hatchability trials were initiated by the selection of five females from each replicate. Selection was made when at least five females produced an egg mass in that replicate over as short a time period as possible, ideally $24 \mathrm{~h}$. If more than five females produced an egg mass in the time period, then a random selection process was used to select the five females. The selection of synchronized females aimed to reduce the time for the hatchability and juvenile growth trials.

Five consecutive egg masses were collected from each of the selected females, resulting in 25 egg masses per replicate and 75 egg masses per treatment level. The number of eggs per egg mass was counted for each of these egg masses. Each egg mass was placed separately in a glass and nylon mesh basket submerged in the test solutions. The time, in days, to first hatch and approximate time to $50 \%$ hatch were recorded. Each egg mass was observed for 2 weeks following first hatch. Any eggs not hatched by this time were defined as nonviable (Forbes et al., accepted).

Effects of BPA on egg hatchability were tested by calculating average percent hatch for each mother (mean of 5 egg masses), transforming the data to improve normality (arcsine transformation, following Sokal and Rohlf, 1995) and performing a nested ANOVA, with replicate aquaria nested within treatments. The number of days to first and $50 \%$ hatch were analyzed similarly, though for these endpoints it was not necessary to transform the data prior to analysis.

\subsection{Juvenile growth trial}

A juvenile growth trial was performed for an exposure period of 3 months and was conducted as a continuation of the hatchability trial. The growth trial was initiated when the first of the five females used for the hatchability trial produced her fifth egg mass. On this date egg masses were collected from the same five females used for the hatchability trial and transferred to hatching baskets as above. Between 15 and 20 juvenile snails were impartially selected from each egg mass of each selected female on the day of $50 \%$ hatch. The selected snails were held at a maximum density of 2 snails/L. At 30 days post-hatch (dph), five juvenile snails were selected randomly from the original 15-20, blotted dry and weighed. At 37 dph all snails were blotted dry, individually identified by numbering the shell using a fine point permanent marker, and weighed. Unpublished pilot trials showed that this procedure did not adversely affect snail growth or survival. Subsequently, the 25 snails (five from each of the five females) were placed in an aquarium of the same dimensions as used in the adult fecundity trial but without the partitions and with a working volume of $32 \mathrm{~L}$ (at a density of 0.8 snails/L). Snail wet weights were measured to the nearest $0.1 \mathrm{mg}$ on a laboratory balance after gently blotting excess water from snails.
Juvenile growth rates were calculated by fitting a third degree polynomial to the data set for each individual, and calculating the growth rate at $60 \mathrm{dph}$ from the equations. Only individuals with at least four data points were used to estimate the parameters of the polynomial function. Growth rates were compared by nested ANOVA (with replicate aquaria and mothers nested within treatments).

\subsection{Statistical power analysis}

The power to observe an effect on the total egg production was calculated using the method described in van der Hoeven (1998) assuming that the two-sided Dunnett test was used to compare the replicate means in the different treatments with those in the control. The among-replicate coefficient of variation $(\mathrm{CV})$ was estimated from this data set.

\section{Results}

\subsection{Analytical chemistry}

In general, measured concentrations of BPA were close to or greater than nominal concentrations (Table 1). Recoveries were generally closer to nominal values in the Adult Fecundity Trial than in the Egg Hatchability and Juvenile Growth Trials. The latter two trials are considered together due to differences in starting dates of the grow-out portion (0-37 days post hatch) among replicates such that some of the analytical samples cover both portions of testing. The lowest average recovery occurred in the $16 \mu \mathrm{g} / \mathrm{L}$ treatment in the Hatchability/Juvenile Growth Trial in which average recovery was $75 \%$ of nominal. The highest recovery occurred in the $0.1 \mu \mathrm{g} / \mathrm{L}$ treatment in the Hatchability/Juvenile Trial in which average recovery was $143 \%$ of nominal.

\subsection{Adult fecundity trial}

There was 100\% survival of adult snails in all treatments during the course of the 12 -week trial. There was no significant effect of BPA on adult egg production at any of the tested concentrations $(P=0.42)$ (Figure 1$)$, nor were there any significant differences among replicates within treatments $(P=0.24)$. Of the 180 snail pairs used in this trial, five pairs did not produce any eggs, and these infertile pairs were omitted from the analysis (Control: 1 pair; $0.1 \mu \mathrm{g} / \mathrm{L}: 2$ pairs; $160 \mu \mathrm{g} / \mathrm{L}: 2$ pairs). Visual inspection

Table 1. Measured concentrations of BPA during the different phases of testing

\begin{tabular}{|c|c|c|c|c|}
\hline \multirow[t]{2}{*}{ Nominal concentration $(\mu \mathrm{g} / \mathrm{L})$} & \multicolumn{2}{|c|}{ Adult fecundity trial } & \multicolumn{2}{|c|}{ Hatchability/Juvenile growth trial } \\
\hline & Measured $(\mu \mathrm{g} / \mathrm{L})$ & $\%$ of Nominal & Measured $(\mu \mathrm{g} / \mathrm{L})$ & $\%$ of Nominal \\
\hline 0.1 & $0.10(0.03)$ & 101 & $0.14(0.03)$ & 143 \\
\hline 1.0 & $1.01(0.13)$ & 101 & $1.22(0.11)$ & 122 \\
\hline 16.0 & $13.70(0.91)$ & 86 & $12.00(3.65)$ & 75 \\
\hline 160 & $155(28.7)$ & 97 & $157(38.5)$ & 98 \\
\hline 640 & 607 (147.5) & 95 & $682(160.5)$ & 106 \\
\hline
\end{tabular}

Values are means (SD) based on a total of 15 (Adult Trial) or 22 (Hatchability/Juvenile Growth) samples taken over the course of the trials. 


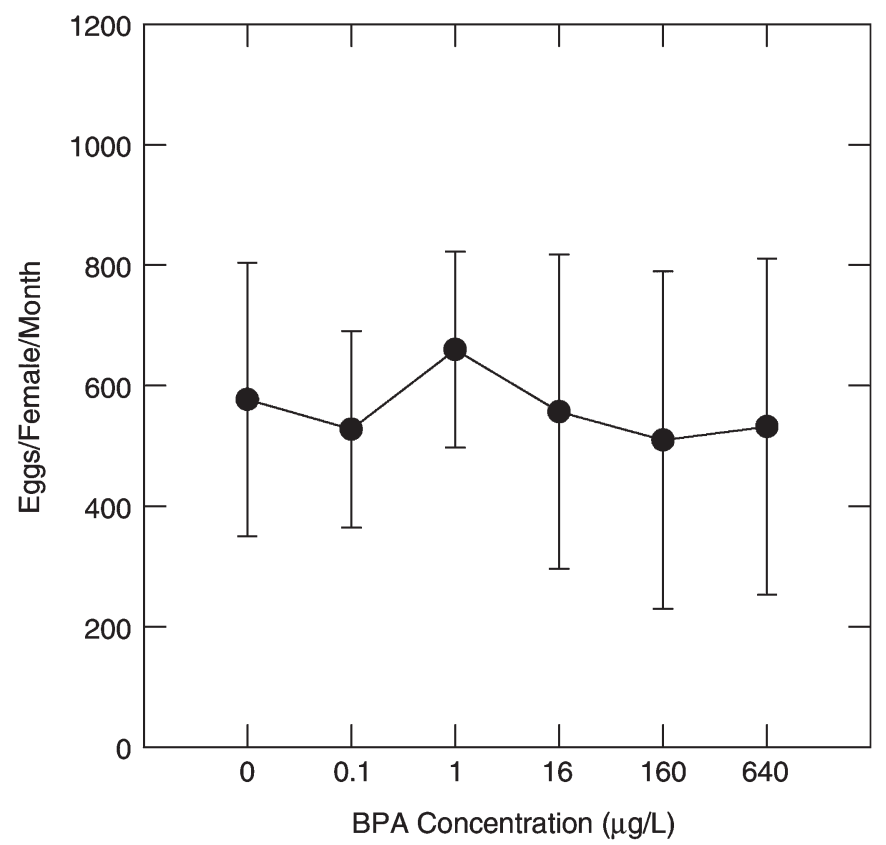

Figure 1. Adult Fecundity Trial: Mean number of eggs/female/month as a function of BPA concentration $(\mu \mathrm{g} / \mathrm{L})$. Error bars are $95 \%$ confidence limits around replicate means $(n=3$ per concentration).

of reproductive output during the course of the trial does not indicate any clear time trends (either increasing or decreasing) in egg production as a function of increasing exposure time (Figure 2).

Snails produced an average of 560 eggs/female/ month (averaged over all treatments and pairs). The contribution of BPA concentration to the total variance in egg production was estimated by treating the effect of BPA levels as a random factor, just as the replicate effect.

This analysis indicated that only $0.4 \%$ of the total variance in egg production could be attributed to BPA treatment, whereas $2.6 \%$ was due to replicate and $97 \%$ was due to inter-individual variability. The within-replicate (aquarium) coefficients of variation for this endpoint provide an estimate of the size of inter-snail variability. These ranged from $27 \%$ to $66 \%$ and averaged $45 \%$.

\subsection{Egg hatchability trial}

There was no effect of BPA exposure on percent hatch $(P=0.51)$ (Figure 3$)$ and no significant difference in percent hatch among replicate aquaria within treatments $(P$ $=0.34)$. Likewise, we could detect no effect of BPA exposure on time to first hatch $(P=0.10)$ or $50 \%$ hatch $(P=$ $0.16)$ (Figure 4$)$, and there were no differences among replicates within treatments for either endpoint $(P=0.79$ for first hatch and $P=0.78$ for median hatch).

Percent hatch (for all mothers and treatments pooled) averaged 93\% (SD = 15.5), time to first hatch took an average of 11.5 days $(S D=0.91)$ and time to $50 \%$ hatch took an average of 12.2 days $(\mathrm{SD}=2.19)$.

Analysis of the contribution of BPA concentration to the total variance in hatchability traits indicated that only a very small percent of the total variance in percent hatch (ca. 0\%), time to first hatch (6\%) and time to $50 \%$ hatch $(4 \%)$ could be attributed to BPA treatment. By far the largest contributor to the total variance in hatchability traits was due to inter-individual variability (which accounted for approximately 95\% of the total variance for all three traits). The average within-replicate coefficient of
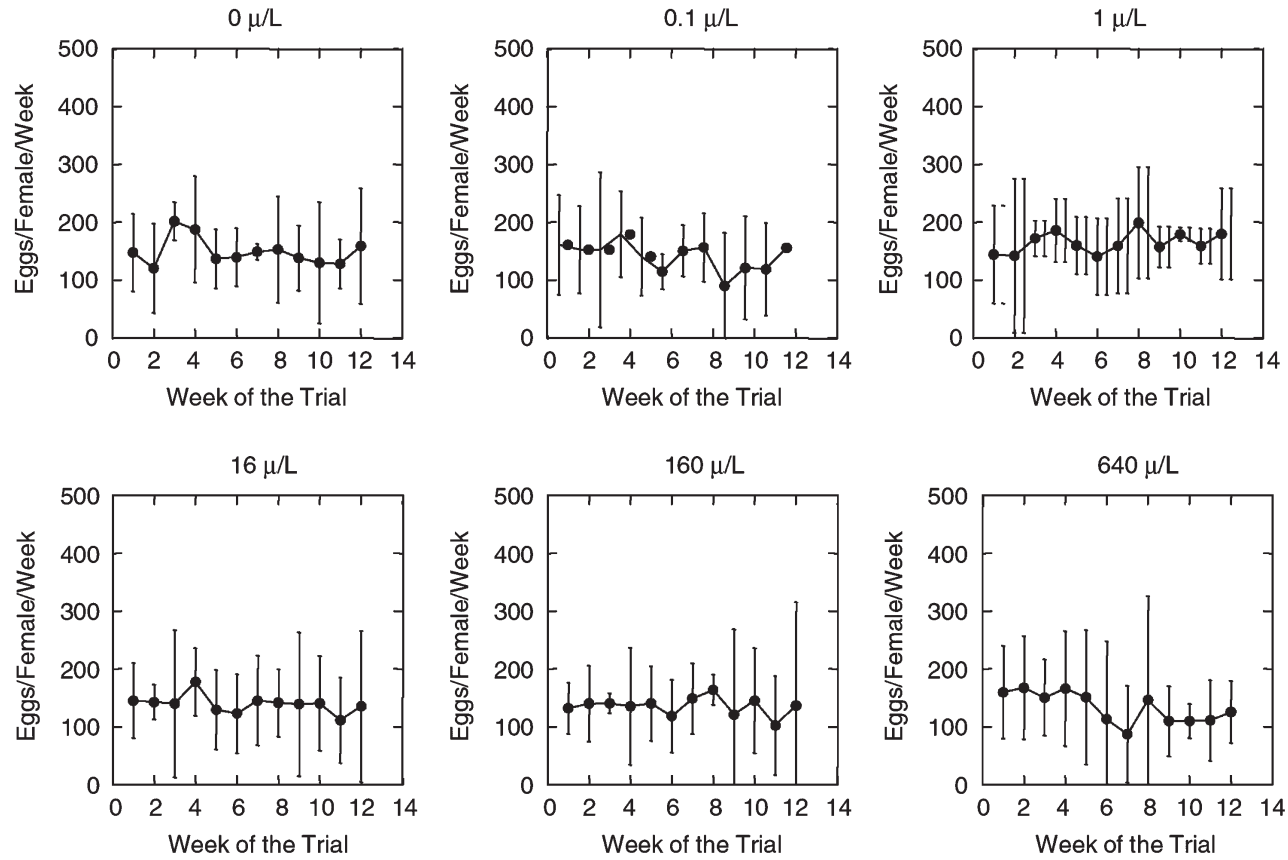

Figure 2. Adult Fecundity Trial. Mean time trends in weekly reproductive output during the course of the trial. Error bars are $95 \%$ confidence limits around replicate means ( $n=3$ per concentration). 
variation for percent hatch was $18 \%$ (range: 6-65\%), for time to first hatch was 6\% (range: 2-22\%), and for time to $50 \%$ hatch was $9 \%$ (range: $3-56 \%$ ).

\subsection{Juvenile growth trial}

Of the 450 juveniles tested in this trial (75 juveniles per treatment), only two did not survive until the end of the trial, both in the $640 \mu \mathrm{g} / \mathrm{L}$ treatment, giving a survivorship of $>97 \%$ in all treatments. Snails increased rapidly in size in the control and all BPA treatments. The growth rates (g/day) and wet weights at $60 \mathrm{dph}$ are shown in Figure 5. Results of the nested ANOVA (with BPA concentration as a fixed effect and the replicates and snail parent pairs as random effect factors) found the effect of BPA to be nonsignificant $(p=0.07)$. This was confirmed by Dunnett's test comparing replicate means between each of the BPA concentrations with the control $\left(p_{\text {(two-sided) }}>0.1\right.$ for all comparisons).

Analysis of the contribution of BPA concentration to the total variance in juvenile growth rate indicated that only $9.2 \%$ of the total variance in wet-weight growth was due to BPA concentration, $7.8 \%$ was due to replicate, $24.5 \%$ was due to the effect of parent and $58.5 \%$ was due to inter-individual variance. Thus the variance due to BPA is of the same order as the variance due to replicate, and the major source of variation in juvenile growth was due to interindividual variation. The average coefficient of variation for growth rate, among individual snails within replicate aquaria, was $28 \%$ and ranged from $20 \%$ to $37 \%$.

\subsection{Statistical power analysis}

For the power analysis, we focused on the adult fecundity data because this trait showed a higher degree of inter-individual variability than egg hatchability or juvenile growth. The $\mathrm{CV}$ for the mean egg production among replicates within treatments was estimated to be $15 \%$. For a fixed total number of replicates, the power is maximum if the number of replicates in the control is about $k^{0.5}$ as large as the number of replicates in each of the $k$ concentration levels. Using a two-sided test, an increase or decrease in egg production of $20 \%$ can be observed with a power of $52 \%$ if 4 concentration levels are compared with the control, and 6 replicates are used per treatment and 12 in the control. With a power of $80 \%$ an effect of $25.9 \%$ can be observed with this design. To observe with a power of $80 \%$ an effect of $20 \%$ on egg production, 20 replicates in the control, and 10 in the treatments would be needed.

\section{Discussion}

We observed no effects of BPA exposure on survival or reproductive output of $M$. cornuarietis during a 12-week exposure period to concentrations in the range 0.1-640 $\mu \mathrm{g} / \mathrm{L}$. Average egg production rates (560 eggs/female/ month) were markedly higher than those observed by

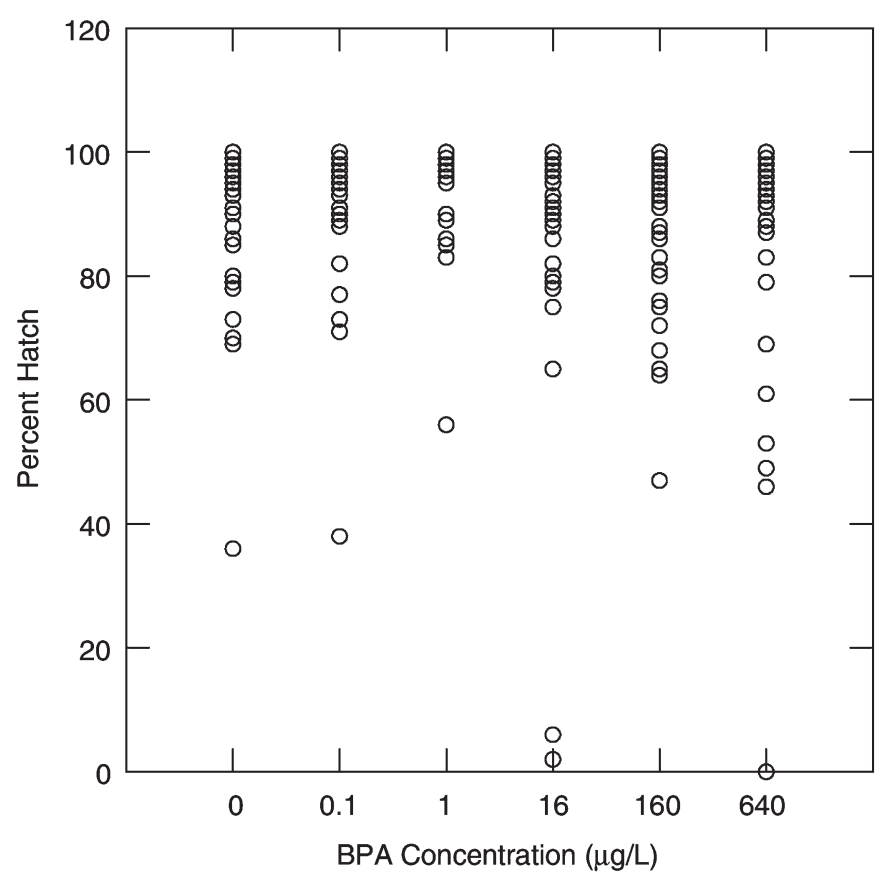

Figure 3. Egg Hatchability Trial. Percent hatch of egg masses produced by adult snails under different BPA exposure treatments. Values shown are means (based on $n=5$ clutches) for each of the 25 females per concentration.

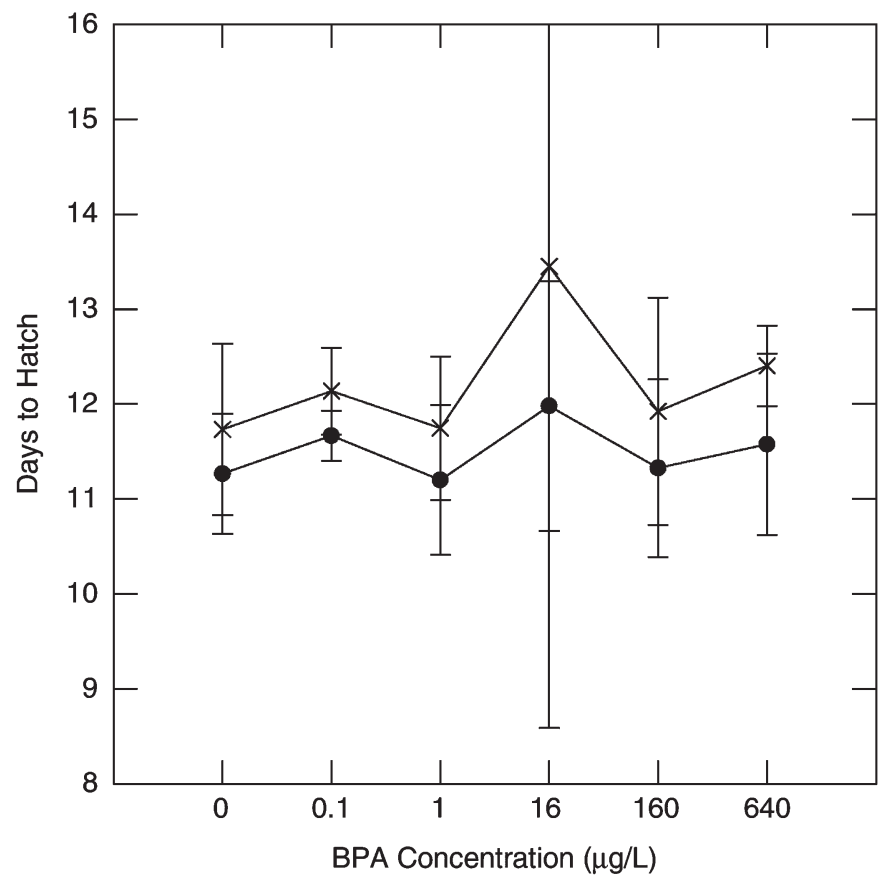

Figure 4. Egg Hatchability Trial. Mean time to first (circles) and $50 \%$ (crosses) hatch for egg masses exposed to different BPA treatments. Error bars are $95 \%$ confidence limits around replicate means ( $n=3$ per concentration).

Oehlmann et al. (2000; 2006a; peak rates were ca. 30-180 eggs/female/month), and we observed substantial intersnail variability in this endpoint. Likewise, we observed 

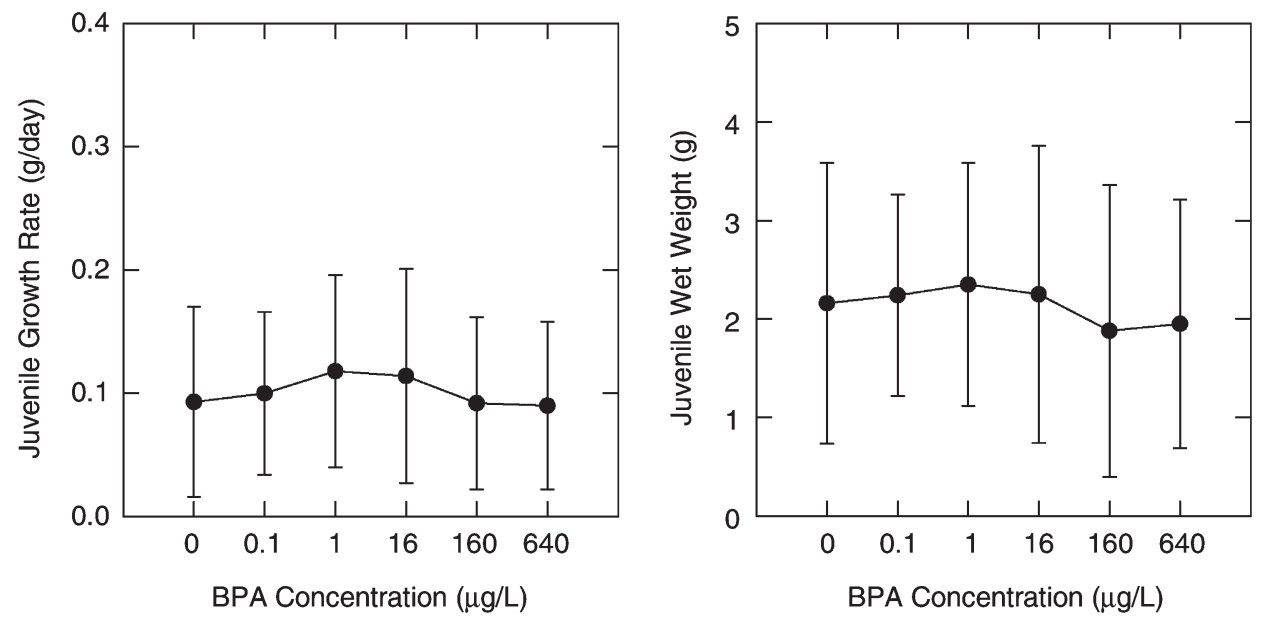

Figure 5. Juvenile Growth Trial. Mean growth rates (a), and wet weights at 60 days post-hatch (b), for juvenile snails exposed to different BPA treatments. Error bars are $95 \%$ confidence limits around replicate means ( $n=3$ per concentration).

no effects of BPA exposure on egg hatchability, and egg masses in all treatments showed high hatchabilities that averaged over $90 \%$. Eggs within and between egg masses hatched nearly synchronously with about a day between first-and $50 \%$ hatch. No effects of BPA exposure on the timing of hatching were observed. Juveniles showed high survival and good growth in the control and all treatments, and had reached a size of about $2 \mathrm{~g}$ (wet weight) by 60 days of age. Growth rates were within the range estimated from the baseline trial (Forbes, et al., accepted), and there were no significant effects of BPA exposure on this endpoint.

The results observed in this study deviate substantially from those of Oehlmann and colleagues. Oehlmann et al. (2000) claimed to detect statistically significant stimulation of egg production in $M$. cornuarietis exposed to nominal BPA concentrations as low as 1 $\mu \mathrm{g} / \mathrm{L}$. However, since only one replicate was used for each treatment, the reported statistical tests are invalid. Oehlmann et al. (2006a) reported to observe significant stimulation of egg production for snails exposed to nominal BPA concentrations of $0.1,0.5$ and $1 \mu \mathrm{g} / \mathrm{L}$ during a total exposure period of 180 days. However, marked variation in snail reproductive output occurred over time in this study (which was attributed to seasonality in spawning), and it was claimed that effects of BPA were only detectable outside of the main spawning season (i.e., days $0-65$ and days $145-180$ of the study), which Oehlmann et al. (2006a) reported to occur from November to January. In the present study, which was conducted from August 26to November 11, 2005, (i.e., outside of the purported main spawning season according to Oehlmann et al., 2006a), we observed both higher reproductive rates than Oehlmann et al. (2006a) and no effect of BPA exposure on egg production.

Using a nested design that permitted identification of individual snails, we were able to obtain estimates of inter-snail and inter-aquarium variability. By far the larg- est source of variability for all measured traits was due to variation among individual snails within replicates. Whereas the variance partitioning provides a measure of the relative importance of different sources of variability to traits, the coefficient of variation provides an estimate of the degree of variability in traits that is independent of the scale on which traits are measured. In the present study, we found that reproductive output was the most variable trait (average within-replicate coefficient of variation $=45 \%)$, followed by juvenile growth $(\mathrm{CV}=28 \%)$, percent hatch $(18 \%)$, and time to egg hatching (6-9\%). This implies that designing toxicity tests with sufficient power to detect effects on egg production should also be sufficient for detecting effects on the other endpoints.

The high inter-snail variability observed in the present study (see also Forbes et al., accepted) needs to be addressed in both the design and statistical analysis of future toxicity tests. Designs that ignore this important source of variability are likely to produce misleading and potentially irrelevant results. High within- and amongreplicate variability in test endpoints, under tightly controlled laboratory conditions, means that large numbers of test organisms and/or replicates may be needed to statistically detect effects of imposed treatments. It also calls into question the biological significance of minor treatment-related effects that could be easily obscured under field conditions in which a range of natural biotic and abiotic factors are known to have a major influence on organism performance.

Power analysis based on the present results indicates that a relatively high degree of replication is needed to detect effects on reproduction of $M$. cornuarietis. Assuming four treatments plus a control, we estimated that detecting a $26 \%$ treatment effect on egg production with $80 \%$ power would require the use of six replicates per treatment and 12 replicates in the control, or a total of 36 tanks and 360 snails. For the same total number of tanks, we determined that this design is more powerful than a design 
using additional treatment concentrations and/or a design with an equal number of replicates in the control and treatment groups. Given the amount of space required to house these animals (ca. 1.25 L per snail), the need for flow-through systems to maintain water quality and constant toxicant exposure, and the replication needed to account for inter-snail variability are among the disadvantages of using $M$. cornuarietis in toxicity testing.

The results of the present study can be used to improve test design so that relevant effects of BPA on snail performance can be detected. We recommend that future tests maintain a nested design, in which individual snails can be identified, but that the degree of replication and the allocation of replicates among treatments be improved so as to reduce the minimum detectable effect size for reproductive output as much as practically feasible.

\section{Conclusion}

In conclusion, the results of the present study do not support previous claims of enhanced reproduction in Marisa cornuarietis in response to exposure to low concentrations of BPA. The present study was conducted using a more robust experimental design and more appropriate statistical methods than previously published studies of BPA effects on this species, and furthermore allowed intra-and inter-snail variability in response to BPA to be quantified. However, statistical power analyses indicate that, particularly for fecundity traits, even higher levels of replication (i.e., about twice that used here) are desirable for detecting effects of BPA with an acceptable degree of confidence. The results will be used to inform the design of future toxicity tests with this species.

Acknowledgments - We are grateful to Gary Klecka (The Dow Chemical Company), Ellen Mihaich (Consultant to GE Advanced Materials), Charles Staples (Assessment Technologies, Inc.), Steven Hentges (American Plastics Council), and David Thomas (Consultant to PlasticsEurope) for helpful discussions and valuable comments on the manuscript. Financial support was provided by the Bisphenol A Global Industry Group.

Funding source - This work was funded by the Bisphenol A Global Industry Group. All experiments were conducted in accordance with national and institutional guidelines for the protection of animal welfare.

\section{References}

Aufderheide, J., Warbritton, R., Pounds, N., File-Emperador, S., Staples, C., Caspers, N., Forbes, V., 2006. The effects of husbandry parameters on the life-history traits of Marisa cornuarietis: effects of temperature, photoperiod and population density. Invert. Biol. 125, 9-20.
Creed, J.T., Brockhoff, C.A., Martin, T.D., 1994. Determination of Trace Elements in Waters and Wastes by Inductively Coupled Plasma-Mass Spectrometry, Method 200.8, Revision 5.4 EMMC Version. US Environmental Protection Agency.

Dietrich, D.R., O'Brien, E., Hoffmann, S., Balaguer, P., Nicolas, J-C., Seinen, W., Depledge, M., 2006. Effects of BPA in snails. Environ. Health Persp. 114, A340-A341.

EC 2003. European Union Risk Assessment Report: Bisphenol A-3rd Priority List, volume 37. Institute for Health and Consumer Protection. Joint Research Centre. Ispra, Italy. Available at: http://ecb.jrc.it/DOCUMENTS/Existingchemicals/RISK ASSESSMENT/REPORT/bisphenolareport325.pdf

Forbes, V.E., Calow, P., 1999. Is the per capita rate of increase a good measure of population-level effects in ecotoxicology? Environ. Toxicol. Chem. 18 (7), 1,544-1,556.

Forbes, V.E., Selck, H., Palmqvist, A., Aufderheide, J., Warbritton, R., Pounds, N., Thompson, R., van der Hoeven, N., Caspers, N., 2007. Does bisphenol A induce superfeminization in Marisa cornuarietis? Part I: Intra- and inter-laboratory variability in test endpoints. Ecotoxicol. Environ. Saf. 66, 307-318.

Mount, D.I., Brungs, W.A., 1967. A simplified dosing apparatus for fish toxicological studies. Water Res. 1, 21-29.

OECD, 1997. Organization for Economic Cooperation and Development. Decision of the Council, Revised Principles of Good Laboratory Practices [C (97) 186/Final].

Oehlmann, J., Schulte-Oehlmann, U., Tillmann, M., Markert, B., 2000. Effects of endocrine disruptors on prosobranch snails (Mollusca: Gastropoda) in the laboratory. Part I: bisphenol A and octylphenol as xeno-estrogens. Ecotoxicology 9, 383-397.

Oehlmann, J., Schulte-Oehlmann, U., Bachmann, J., Oetken, M., Lutz, I., Kloas, W., Ternes, T.A., 2006a. Bisphenol A induces superfeminization in the ramshorn snail Marisa cornuarietis (Gastropoda: Prosobranchia) at environmentally relevant concentrations. Environ. Health Persp. 114 (Suppl 1), 127-133.

Oehlmann, J., Schulte-Oehlmann, U., Bachmann, J., Oetken, M., Lutz, I., Kloas, W., Ternes, T.A., 2006b. Effects of BPA in snails: Oehlmann et al. respond. Environ. Health Persp. 114, A341-A342.

Schulte-Oehlmann, U., Tillmann, M., Casey, D., Duft, M., Markert, B., Oehlmann, J., 2001. Östrogenartige Wirkungen von Bisphenol A auf Vorderkiemenschnecken (Mollusca: Gastropoda: Prosobranchia). UWSF-Z Umweltchem Ökotox 13, 319-333.

Sokal, R.R., Rohlf, F.J., 1995. Biometry, $3^{\text {rd }}$ ed. W.H. Freeman and Company, New York.

Staples, C.A., Dorn, P.B., Klecka, G.M., O’Block, S.T., Harris, L.R., 1998. A review of the environmental fate, effects and exposures of bisphenol A. Chemosphere 36 (10), 2,149-2,173.

Staples, C.A., Woodburn, K., Caspers, N., Hall, A.T., Klecka, G., 2002. A weight of evidence approach to the aquatic hazard assessment of bisphenol A. Hum. Ecol. Risk Assess. 8, 1,083-1,105.

Van der Hoeven, N., 1998. Power analysis for the NOEC: what is the probability to detect small toxic effects on three different species using the appropriate standardized test protocols? Ecotoxicology 7, 355-361. 